\title{
O DIA-A-DIA DOS ARTISTAS DE RUA DA REGIÃO CENTRAL DE SÃO JOSÉ DOS CAMPOS E JACAREÍ: COMO ELES SE VEEM INSERIDOS NA SOCIEDADE
}

\author{
Márcia Borges de Campos ${ }^{1}$ \\ Mariana Donda de Carvalho Coutinho Carolino ${ }^{2}$ \\ Thiago Vinícius Lima da Silva ${ }^{3}$ \\ Silene Fernandes Bicudo ${ }^{4}$
}

\begin{abstract}
Resumo: O artigo visa abordar as dificuldades vividas no dia-a-dia de trabalho de artistas de rua nas regiões centrais das cidades de São José dos Campos e Jacareí, cujo propósito é de, através do levantamento de dados por aplicação de questionários, desconstruir o estereótipo que a sociedade, ainda que inconscientemente, Ihes atribuem. Conhece-se a visão das autoridades e da fiscalização, bem como a visão que a grande maioria da sociedade tem em relação a estes artistas, porém pouco se ouve falar sobre o lado dos próprios artistas nos veículos de comunicação em geral. Pretende-se através deste artigo, dar voz a tais artistas, e ressaltar que, ainda, atualmente, julga-se um livro pela capa.

Palavras-chave: Contracultura; Manifestação; Preconceito; Arte; Artista de rua.
\end{abstract}

\footnotetext{
${ }^{1}$ FCSAC - Faculdade de Ciências Sociais Aplicadas e Comunicação/Univap - Univerdidade do Vale do Paraíba, Brasil. E-mail: marciabcampos@outlook.com.

2 FCSAC - Faculdade de Ciências Sociais Aplicadas e Comunicação/Univap - Univerdidade do Vale do Paraíba, Brasil. E-mail: mah_donda@yahoo.com.br.

3 FCSAC - Faculdade de Ciências Sociais Aplicadas e Comunicação/Univap - Univerdidade do Vale do Paraíba, Brasil. E-mail: thunivap.radiotv@gmail.com.

${ }^{4}$ FCSAC - Faculdade de Ciências Sociais Aplicadas e Comunicação/Univap - Univerdidade do Vale do Paraíba, Brasil. E-mail: silene@univap.br.
} 